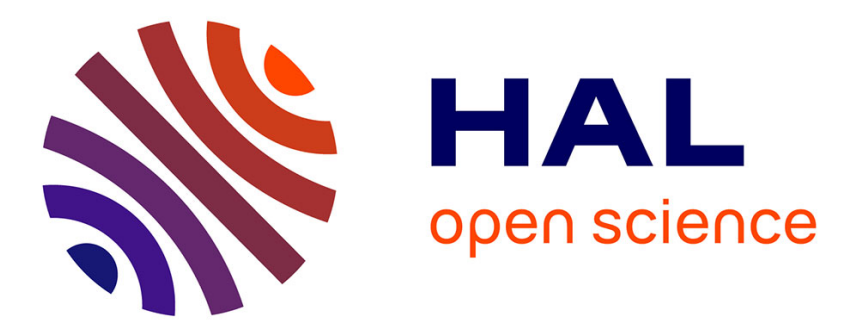

\title{
A Low-Energy Emulsification Batch Mixer For Concentrated Oil-In-Water Emulsions
}

Sylvain Caubet, Yves Le Guer, Bruno Grassl, Kamal El Omari, Eric

Normandin

\section{To cite this version:}

Sylvain Caubet, Yves Le Guer, Bruno Grassl, Kamal El Omari, Eric Normandin. A Low-Energy Emulsification Batch Mixer For Concentrated Oil-In-Water Emulsions. 2009. hal-00395299

\section{HAL Id: hal-00395299 \\ https://hal.science/hal-00395299}

Preprint submitted on 15 Jun 2009

HAL is a multi-disciplinary open access archive for the deposit and dissemination of scientific research documents, whether they are published or not. The documents may come from teaching and research institutions in France or abroad, or from public or private research centers.
L'archive ouverte pluridisciplinaire HAL, est destinée au dépôt et à la diffusion de documents scientifiques de niveau recherche, publiés ou non, émanant des établissements d'enseignement et de recherche français ou étrangers, des laboratoires publics ou privés. 


\title{
A LOW-ENERGY EMULSIFICATION BATCH MIXER FOR CONCENTRATED OIL-IN-WATER EMULSIONS
}

\author{
Sylvain CAUBET ${ }^{a, b}$, Yves LE GUER ${ }^{a *}$, Bruno $\operatorname{GRASSL}^{b}$, \\ Kamal EL OMARI ${ }^{a}$ and Eric NORMANDIN ${ }^{c}$ \\ ${ }^{a}$ Laboratoire de Thermique Energétique et Procédés (LaTEP). \\ ${ }^{b}$ Institut Pluridisciplinaire de Recherche Environnement et Matériaux \\ (IPREM UMR 5244) - Equipe de Physique et Chimie des Polymères (EPCP). \\ ${ }^{c}$ Plateau Innov'Adour. \\ ${ }^{a, b, c}$ Université de Pau et des Pays de l'Adour (UPPA), \\ Hélioparc, Avenue P. Angot - 64000 Pau, France. \\ Submited to AICHE Journal
}

\begin{abstract}
The presented work shows the formation of a monodisperse High Internal Phase Ratio (HIPR) Oil-in-Water $(\mathrm{O} / \mathrm{W})$ emulsion using a new type of a two-rod batch mixer. The mixture components have sharply different viscosities $(1 / 3400$ for $\mathrm{W} / \mathrm{O})$ and similar densities $(1 / 0.974$ for $\mathrm{W} / \mathrm{O})$. The oil ratio in the mixture remains constant at $91 \%[\mathrm{w} / \mathrm{w}]$ for each experiment. The simple design of the new mixer leads to a low-energy process, characterized by very low rotational speed, laminar flow and no need for fluid heating. The droplet size distribution during the emulsification was investigated according to different physical and formulation parameters such as stirring time, rotational speed, surfactant type, concentration, and salt addition. We show that all studied parameters except salt addition allow a precise control of the concentrated emulsion droplet size distribution, which governs the rheological behavior of the emulsion and its stability. The formed HIPR emulsion shows two shear-thinning domains.

This work was presented at the 2009 conference of the French Chemical Engineering Society (Marseille, SFGP 2009)
\end{abstract}

Keywords : Batch mixer, Low energy emulsification, Concentrated emulsions, Droplet size distribution control.

\section{Introduction}

To disperse a fluid into another immiscible fluid, some mechanical energy, e.g., shear, is applied, together with a surfactant, to produce a dispersion with stable properties, including final droplet size, polydispersity and rheology. The nature of the two fluids, the surfactant and the process conditions (design of the mixer, mixing rate and time) all have a critical effect on the properties of the final emulsion. During the process of emulsification, external shear energy is used to break large drops into smaller ones. For an internal volume ratio above 0.74, emulsions are called High Internal Phase Ratio (HIPR) emulsions, bi-liquid foam systems or gel emulsions [1]. HIPR emulsions are encountered in a wide variety of industrial applications: petrochemical for bitumen or heavy crude oils [2]; agrochemicals; pharmaceuticals; cosmetics; etc. The main works of Princen [3, 4] have shown the rheological and structural properties of gel emulsions. Most of the proprieties of gel emulsions, particularly the rheological behavior, are affected by the droplet size distribution, the volume fraction and the interfacial tension between oil and water [5, 6]. Thus, during the emulsification process, the droplet size

${ }^{*}$ Corresponding author : yves.leguer@univ-pau.fr 
distribution is an important parameter to control to obtain a HIPR emulsion with the desired properties. This depends on several parameters, such as the process, the surfactant, the water/oil ratio, the type of oil (vegetable, synthetic, bitumen, etc.) and other formulation and physical parameters used for the mixing. Typically, the droplet diameter can vary from one to hundreds of micrometers. Rheological studies concerning emulsions have only begun recently and are mostly concerned with "dispersed" emulsions (with an internal volume ratio lower than 0.74 ), while most of HIPR emulsion studies are made on Water-in-Oil (W/O) emulsions [7, 8]. HIPR inverse emulsions $(\mathrm{O} / \mathrm{W})$, which are considered in this work, generally have a shear thinning behavior with viscosity ranging from a few to several thousand Pa.s as a function of the shear rate, the droplet size distribution and the internal volume ratio [9, 19, 11]. Several processes exist to produce HIPR Oil-in-Water emulsions, for example: Coaxial Mixers [12], Colloid Mill [13], High-Pressure Homogenizers [14], Static Mixers [15] or the use of a complex mechanism of the inversion phenomenon [16]. Of course, this list is not exhaustive; other methods and apparata exist for making HIPR O/W emulsions. Here, the issue of mixing effects on the size, distribution and stability of concentrated $\mathrm{O} / \mathrm{W}$ emulsions with contrasting viscosities $(1 / 3,400$ for $\mathrm{W} / \mathrm{O})$ and similar densities $(1 / 0.974$ for $\mathrm{W} / \mathrm{O})$ is addressed for a new type of laminar batch mixer. The HIPR emulsions are made in a batch Two-Rod Mixer (TRM) at a high volume ratio (0.91) of castor oil in water. We investigate how the droplet size distribution is affected by the variation of physical and formulation parameters such as stirring time, rotational speed, surfactant type and its concentration and addition of salt. Rheological behaviors are also presented.

\section{Materials and Methods}

\subsection{Materials}

The oil used is blown castor oil from Seatons (Ricin oil). It was chosen mainly for its high density $\left(974 \mathrm{~kg} . \mathrm{m}^{-3}\right)$ and high viscosity $\left(3.4 \mathrm{Pa.s}\right.$ at $\left.20^{\circ} \mathrm{C}\right)$. Two well-known non-ionic surfactants were used and compared: Triton X-405 (HLB = 17.9, CMC in water of $0.159[w t / w t]$, product of Sigma-Adrich) and Triton X-100 (HLB = 13.5, CMC in water of 0.018 [wt/wt], product of Sigma-Aldrich) [17, 18]. Deionized water, with an electrical conductivity of $18.3 \mathrm{M} \Omega-\mathrm{cm}$, was filtered through a $0.22 \mu \mathrm{m}$ Millipore filter. Sodium chloride $(\mathrm{NaCl})$ was purchased from Sigma-Aldrich.

\subsection{Emulsion preparation}

The experimental setup used to produce the HIPR emulsion was a batch Two-Rod Mixer (TRM, Figure 1 1 (a) and (b)). The larger rod was not coaxial with the tank, and its rotational speed was controlled by a computer. A second, smaller, rod, not rotating, was located next to the first one. The geometrical parameters were as follows: tank diameter $d^{\prime}=150 \mathrm{~mm}$, larger rod radius $r=50 \mathrm{~mm}$, smaller rod diameter $d=15 \mathrm{~mm}$, rod-tank gap $e=3 \mathrm{~mm}$, rod-rod gap $e^{\prime}=2 \mathrm{~mm}$ and the angular position of the smaller $\operatorname{rod} \theta=30^{\circ}$ (Figure 1 (b)). These geometrical parameters remained the same for all of the experiments considered in this study. A system with a strength sensor was adapted to the motor of the larger rod in order to follow the evolution of the resistive torque during the emulsification process. The calculation of the torque and thus of the power input to keep the rotational speed constant can be calculated using the following relations:

$$
\begin{aligned}
& C=F \cdot a \\
& P=C \cdot \Omega
\end{aligned}
$$

where $F$ is the measured strength in newtons; $a$, the distance between the sensor and the axis of the motor $(a=0.185 \mathrm{~m}) ; C$, the torque $(N . m) ; \Omega$, the rotational speed of the larger rod, and $P$, the power $(W)$.

The protocol used to produce the HIPR Oil-in-Water emulsion is as follows. First, $400 \mathrm{~mL}$ of castor oil was added to the tank. Then, the larger rod was rotated at the selected rotational speed $(\Omega=60,90$ or $120 \mathrm{rpm})$. Finally, after one minute, $38.6 \mathrm{~mL}$ of a mixture of distilled water and surfactant was rapidly added into the TRM batch process. The emulsification began at time $t=0 \mathrm{~s}$ 


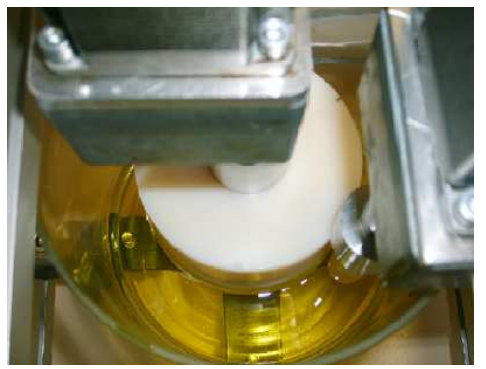

(a)

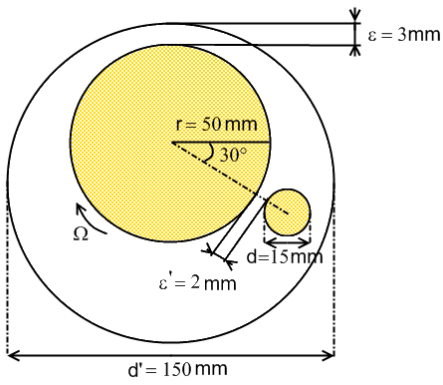

(b)

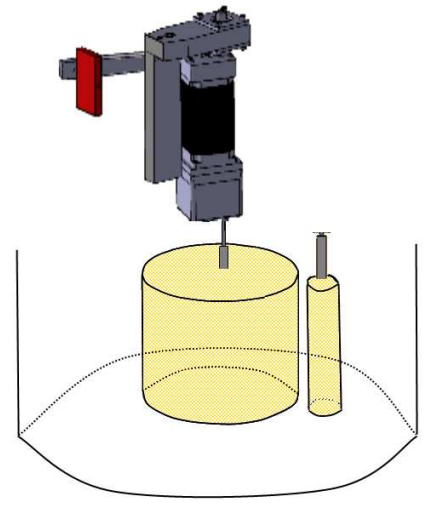

(c)

Figure 1: (a) Photo of the Two-Rod Mixer (TRM) batch device; (b) Schematic of the TRM batch with the dimensions of the elements; (c) 3D view of the TRM equipped with a strength sensor.

when the water-surfactant mixture is added in the tank. The emulsification can be decomposed into three steps. First, the water-surfactant mixture is introduced into the tank. Rapidly thereafter (after a few seconds), the emulsification begins, droplets of oil are formed in the water phase, and all of the Castor oil is gradually dispersed in the water. A crude emulsion is then created, which leads to the formation of the first monodisperse emulsion. The duration $t_{0}$, which corresponds to the creation of this primary monodisperse emulsion, ranges between one and several minutes and depends in particular on the rotational speed of the larger TRM rod (see section 3.2). This initial time $t_{0}$ is an important characteristic time because it represents the limit between two regimes in the evolution of the mean droplet diameter as a function of the mixing time [19]. In the last step, the droplets of the initial monodisperse emulsion are gradually broken into smaller ones. This mechanism induces a reduction of the mean diameter until a limit value is reached (see section 3.1). During the process, the temperature was measured in situ and its variation (in Celcius) did not exceed $10 \%$ of its initial value for all studied rotational speeds.

\subsection{Determination of droplet size distribution}

The droplet size distribution was determined via optical microscopy according to the method described by Tcholakova et al. [20]. The samples, carefully taken from the TRM with a syringe in order to not disturb the mixing, were immediately transferred to $4 \mathrm{wt} \%$ Triton (X-405 or X-100) solutions to prevent further drop coalescence and to reduce the droplet concentration to about 3 vol\% because the original emulsion was too concentrated for droplet size analysis (Figure 2). This dilution was transferred for optical examination into microcapillaries with rectangular cross sections (depth $0.2 \mathrm{~mm}$, width $0.7 \mathrm{~mm}$, length $1 \mathrm{~mm}$ ) no more than $1 \mathrm{~h}$ after their preparation. Before loading the sample into the microcapillary, the vial containing the Triton-stabilized emulsion was gently rotated to homogenize the emulsion. The oil droplets were observed via transmitted light microscopy with a Leica DMLM microscope (magnification $\times 20$ ) connected to a charge-coupled device camera (Leica DFC280) and video recorder software (Leica IM4.0).

The diameters of individual recorded oil droplets were measured using the publicly available software ImageJ 1.40, released by the National Institute of Health (NIH). These data were numerically processed to obtain droplet size histograms. The diameters of at least 800 droplets were measured for each system. Illustrative droplet size histograms are shown in Figure 3 .

The mean diameter $d_{m}$, the mean volume-surface diameter (the Sauter diameter) $d_{32}$ and the uniformity factor $U$ were calculated from the following relations: 


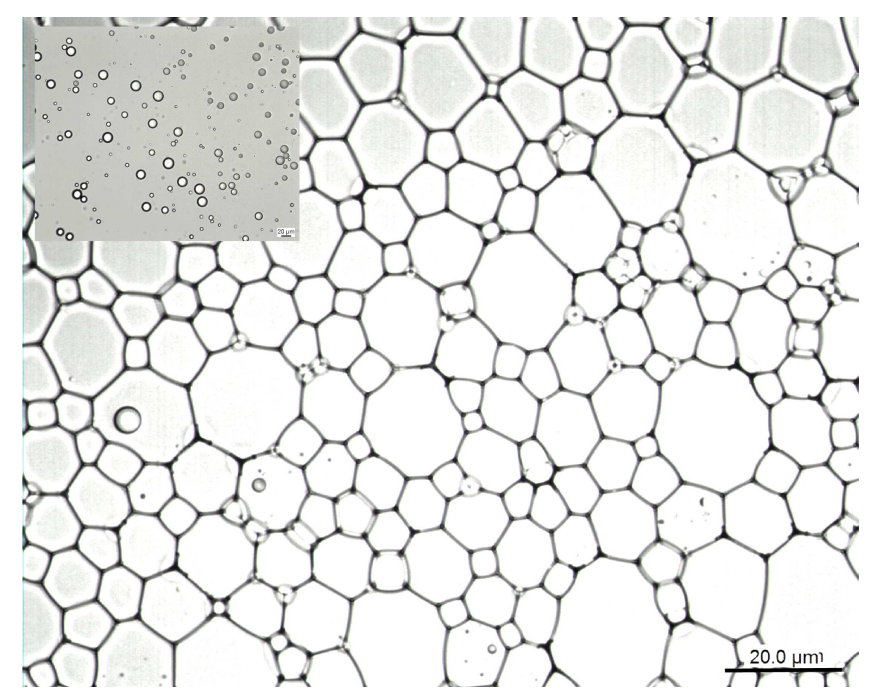

Figure 2: Optical photomicrograph of concentrated emulsion obtained using the batch Two-Rod Mixer process after 780 seconds of mixing with a rotational speed of the rod equal to $90 \mathrm{rpm}$. The surfactant used was $15.9 \mathrm{wt} \%$ Triton X-405 in water. Inset: Optical photomicrograph after dilution. In both cases, the scale bar is $20 \mu \mathrm{m}$.

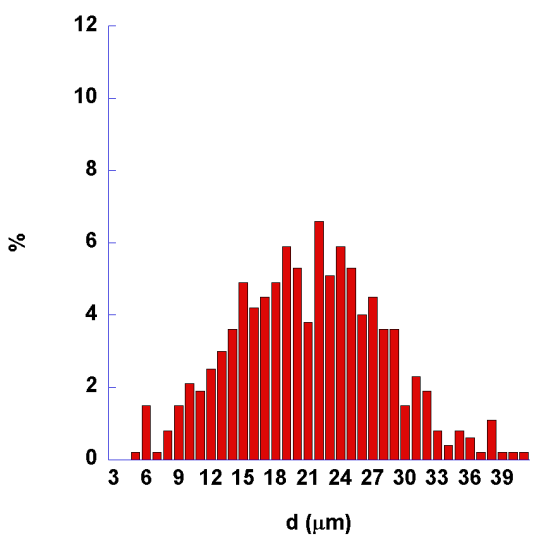

(a)

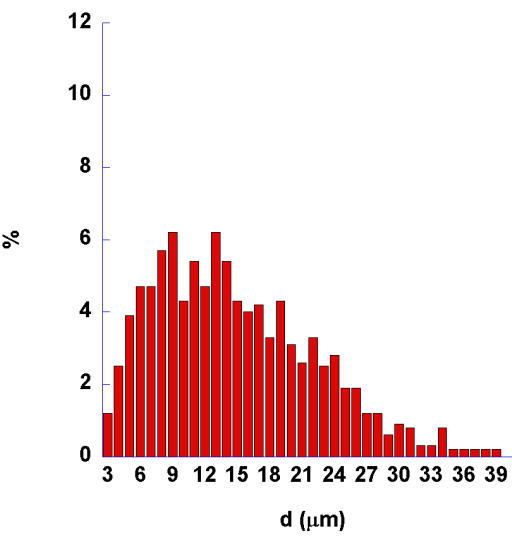

(b)

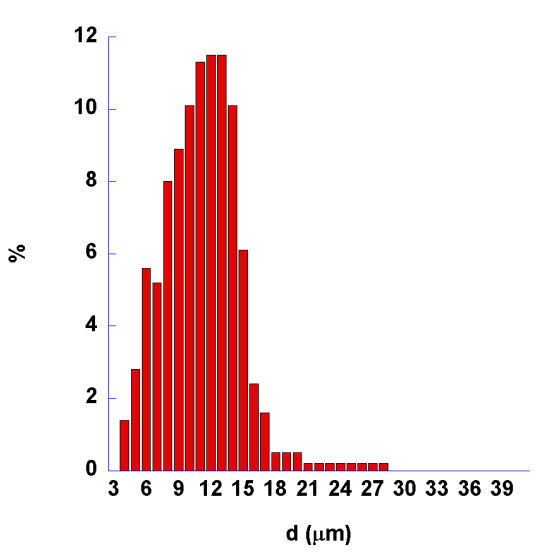

(c)

Figure 3: Evolution of the droplet size distribution during the emulsification in the TRM batch process at a rotational speed of the rod equal to $90 \mathrm{rpm}$. After (a) 300, (b) 780 and (c) 2400 seconds of mixing. The surfactant used was $15.9 \mathrm{wt} \%$ Triton X-405 in water. 


$$
\begin{aligned}
d_{m} & =\frac{\sum n_{i} d_{i}}{\sum n_{i}} \\
d_{32} & =\frac{\sum n_{i} d_{i}^{3}}{\sum n_{i} d_{i}^{2}} \\
U & =\frac{1}{d^{*}} \frac{\sum n_{i} d_{i}^{3}\left|d^{*}-d_{i}\right|}{\sum n_{i} d_{i}^{3}}
\end{aligned}
$$

where $n_{i}$ is the number of droplets of diameter $d_{i}$ and is the median diameter (the diameter for which the cumulative undersize volume fraction is equal to 0.5). Emulsions are considered to be monodisperse if $U$ is smaller than 0.25 [19].

\subsection{Rheological measurements}

The steady shear rheological properties of the HIPR emulsion were measured using a Malvern Bohlin C-VOR 150 rheometer in controlled stress mode with a cone-plate geometry (diameter of $60 \mathrm{~mm}$, cone angle of $2^{\circ}$ ). Stepped shear stress values were selected to study shear rates ranging from 0.1 to $100 \mathrm{~s}^{-1}$. The system was allowed to reach steady state at each shear stress prior to registering the measured values. The measurements were performed by increasing and decreasing the shear stress. Temperature was controlled with a Peltier plate system and was set at $20.0 \pm 0.1^{\circ} \mathrm{C}$.

\section{Experimental results and discussion}

\subsection{Effect of the mixing time on the mean diameter}

In this study, the emulsion was made using a $15.9 \mathrm{wt} \%$ solution of Triton X-405 in distilled water as described in section 2.2. For this experiment, the rotational speed of the rod remained constant and equal to $90 \mathrm{rpm}$ throughout the process. During the emulsification, samples were taken at times $\mathrm{t}=300,420,780,1140,2400$ and $3600 \mathrm{~s}$. The droplet size distribution was then determined, and its probability distribution was plotted for each sampling time (Figure 2). The emulsion can be considered to be monodisperse because its uniformity factor U, calculated using equation (5), is less than or close to 0.25 (Figure 1 ). The evolution of the mean diameter during the mixing over one experiment is shown in Figure 3. Two periods can be distinguished. In the first period, the mean diameter decreases rapidly from $23 \mu \mathrm{m}(\mathrm{t}=180 \mathrm{~s})$ to $15 \mu \mathrm{m}(\mathrm{t}=780 \mathrm{~s})$; i.e., in 600 seconds, $d_{m}$ is reduced by $8 \mu \mathrm{m}$. In the second period, a slower mechanism takes place, and the mean diameter is reduced from 15 to $11 \mu \mathrm{m}$ over 1620 seconds.

A crude emulsion can be transformed into a monodisperse one, as shown by Mason and Bibette [21], who have experimentally discovered this phenomenon by applying a shear step to a crude emulsion. Moreover, Mabille et al. [19] have shown that the fragmentation kinetics of a calibrated emulsion as a function of the initial droplet size involves two distinct regimes. At short timepoints, the droplet diameter decreases abruptly. The droplets deform into long threads that undergo Rayleigh instability. During this regime, the obtained diameter is mainly determined by the applied stress and weakly depends on the viscosity ratio between the dispersed and continuous phases. After this first step, the resulting droplets can, once again, break up into daughter droplets. This second mechanism is much slower, with a characteristic duration of several hundred seconds. Depending on the initial size, the first step can vanish, and only the second slow step persists. In our process, if the crude emulsion was mainly composed of large drops, even after a few seconds of shear, we obtained a wellcalibrated emulsion (with a mean diameter close to $24 \mu \mathrm{m}$ ); all drops deformed into threads of different lengths, but the Rayleigh instability occurs when the same critical radius is reached by each thread. Subsequently, when the first monodisperse emulsion was obtained, the second slow mechanism took place, and since the smaller droplets (between $d_{0}$ and $d_{s}$ ) also broke up, the size distribution became even narrower in the second regime. However, it is clear that the most efficient process to get narrowsize distributions is the initial Rayleigh instability. To fit their experimental data, Mabille et al. [19] 


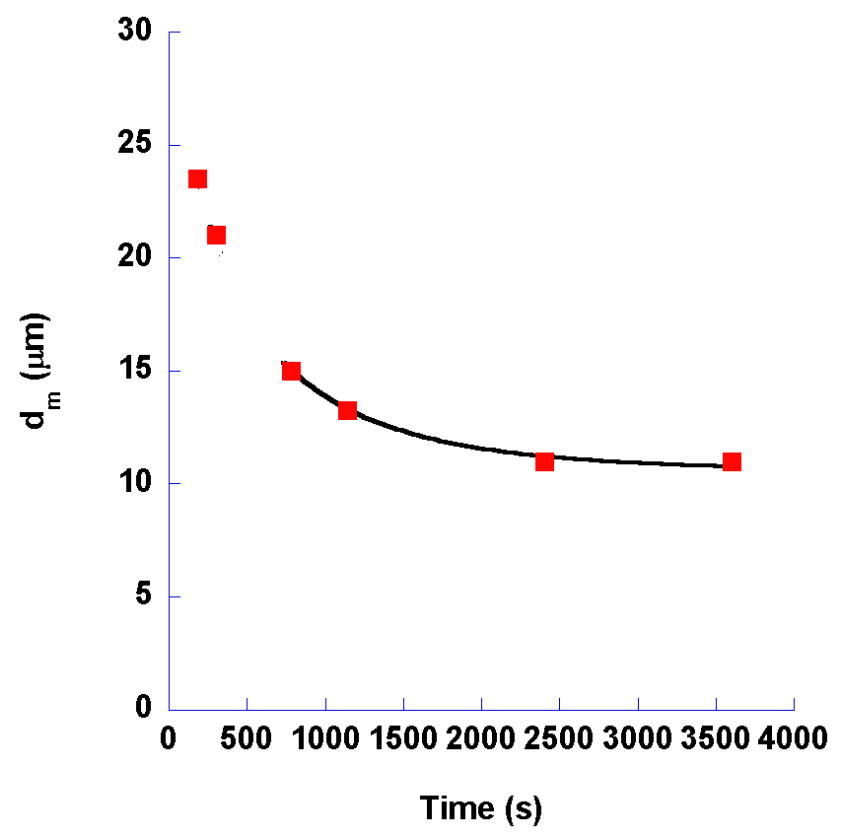

Figure 4: Evolution of the mean droplet diameter during mixing. Points are experimental data, and the line is fitted to experimental data by the use of Eq. (7).

used the following equation:

$$
d_{m}(t)=\frac{d_{s}}{1-\frac{d_{0}-d_{s}}{d_{0}} \exp \left(\frac{-\omega_{0} t}{3}\right)}
$$

In this equation, $d_{0}$ is the diameter of the initial monodisperse emulsion in the slow regime, $d_{s}$ is the saturating diameter, and $\omega_{0}$ is the rupture rate. To examine the kinetics of this fragmentation in our process, we must account for the start of the primary monodisperse emulsion. At the time $t=0 \mathrm{~s}$, we do not have an emulsion; the primary monodisperse emulsion is created during the process at a time defined by $\mathrm{t}=t_{0}$ and corresponding to a drop diameter $d_{0}$. This primary monodisperse emulsion is, in fact, the equivalent of the mother emulsion of Mabille et al. [19] Thus, to fit our data, we have to adapt equation (6) by introducing $t_{0}$ to take into account the time shift and to determine the rupture rate $\omega_{0}$ :

$$
d_{m}(t)=\frac{d_{s}}{1-\frac{d_{0}-d_{s}}{d_{0}} \exp \left(\frac{-\omega_{0}\left(t-t_{0}\right)}{3}\right)}
$$

$t_{0}, d_{0}, \omega_{0}$ and $d s$ are the free parameters used to fit this model (Eq. 7) with our data, using appropriate limit values to fit this equation into the monodisperse regime. Thus, we determine $t_{0}=723 \mathrm{~s}$, $d_{0}=15.4 \mu \mathrm{m}, d_{s}=10.9 \mu \mathrm{m}$, and the rupture rate, $\omega_{0}$, is equal to $0.0039 \mathrm{~s}^{-1}$. This value of $\omega_{0}$ is five times smaller than the one found by Mabille et al. for their process. The inverse of $\omega_{0}$ corresponds to the characteristic fragmentation time of $256 \mathrm{~s}$. Compared to the Rayleigh instability, this regime is extremely long; therefore, the two regimes can be decoupled. This high value of the characteristic fragmentation time is an advantage because it allows the production of different emulsions solely by varying the emulsification time while keeping the same process and the same components. After $\mathrm{t}=$ $2400 \mathrm{~s}$ of mixing, emulsification is achieved, and the mean drop diameter remains constant.

\subsection{Effect of rotational speed on the final diameter}

In this section, the surfactant used was also Triton X-405. The composition, the surfactant concentration, the batch TRM geometry and the protocol used were the same as those previously described. The only variable parameter is the rotational speed of the rod. For each speed studied $(\omega=60$, 
90 and $120 \mathrm{rpm}$ ), the emulsification was performed over 2400 seconds (40 minutes), and the power necessary to maintain constant rotational speed was calculated (Eqs. (11) and (2), Figure 5). The mean droplet diameter $d_{m}$ and the uniformity factor $U$ (Eqs (3) and (5)) were determined at different mixing times for each obtained emulsion and for the different rotational speeds (Figure 6). At the beginning of the emulsification, the power rapidly increased until a certain limit, at which time, its value remained nearly constant. This type of behavior has been previously observed by Sanchez et al. [22] for two types of impellers (anchor and helical ribbon) at different rotational speeds. The main difference observed with their results concerns the early stages of mixing, due to the presence in our process of a macro-mixing step that does not exist in theirs because it represents a pre-emulsification step. This first step can be explained by a lubrication of the rod, leading to a decrease of the measured power. During this macro-mixing phase, the power remains constant until emulsification begins.

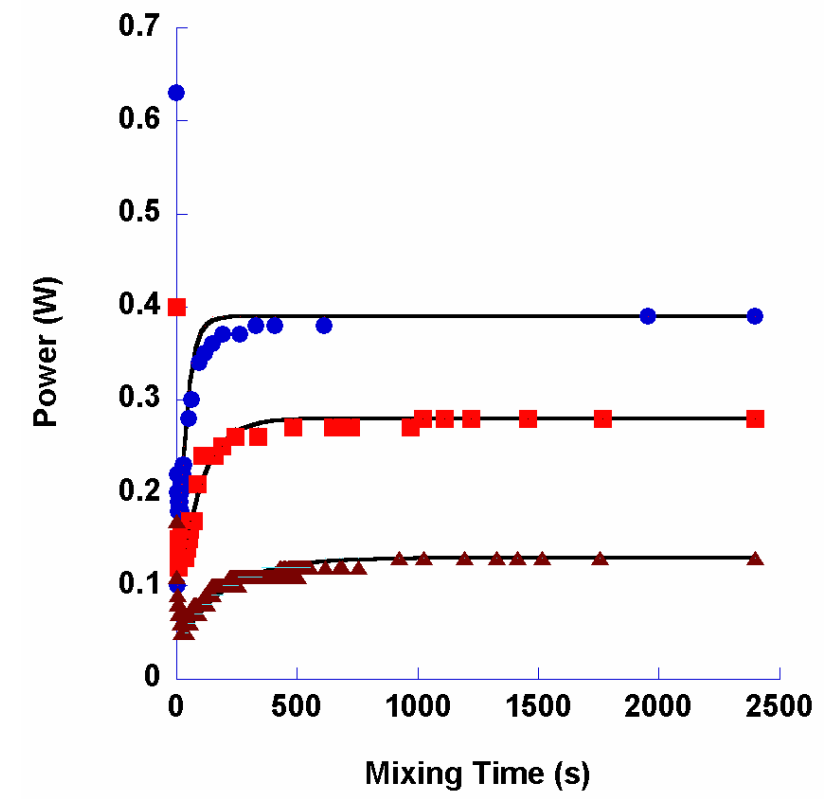

(a)

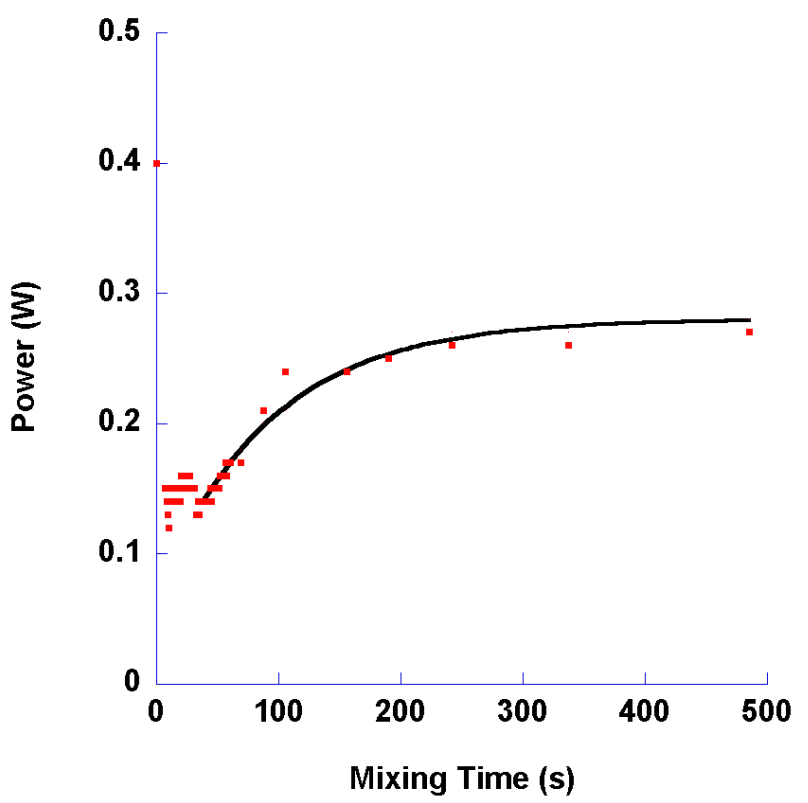

(b)

Figure 5: (a) Evolution of power during the emulsification for different rotational speeds of the rod (circles: $\omega=120 \mathrm{rpm}$, squares: $\omega=90 \mathrm{rpm}$, triangles: $\omega=60 \mathrm{rpm}$ ). Curve fits were obtained using equation (9). (b) Expansion of the early time of mixing for $\omega=90 \mathrm{rpm}$ (the same behavior was observed at all rotational speeds). The surfactant used in each case was $15.9 \mathrm{wt} \%$ Triton X-405 in water.

To fit the experimental data, we adapted the first-order kinetics equation given by Sanchez et al. [22]:

$$
P(t)=P_{e}-P_{e} \exp \left[-k\left(t-t_{m}\right)\right]
$$

To take into account the fact that in our process, we have, contrary to Sanchez et al., a first step in which the power $P$ has an initial value, we adapted equation (8) to obtain:

$$
P(t)=P_{e}+\left(P_{m}-P_{e}\right) \exp \left[-k\left(t-t_{m}\right)\right]
$$

with $P_{e}$ the final power, $k$ the kinetic constant, $t_{m}$ the macro-mixing time, and $P_{m}$ the power at the end of the macro-mixing phase. The values of $k, P_{e}, P_{m}$ and $P_{0}$ (the initial value of the power before addition of the surfactant mixture) are given in Table 1 .

The macro-mixing time $t_{m}$ is shorter for the HIPR emulsion obtained with the rotational speed of $120 \mathrm{rpm}$ and is up to 6 times longer than at 90 and $60 \mathrm{rpm}$, for which it remains roughly equal. The kinetic constant $\mathrm{k}$ and the final power $P_{e}$ decreased with the rotational speed, as was also observed by Sanchez et al. It is important to note that the power input necessary for the formation of the emulsion was always lower than the initial power $P_{0}$ given when only oil is present in the mixer. This is notable 


\begin{tabular}{llll}
\hline$\Omega_{1}(\mathrm{rpm})$ & $120(\mathrm{~W})$ & $90(\mathrm{~W})$ & $60(\mathrm{~W})$ \\
\hline$P_{0}(\mathrm{~W})$ & 0.6 & 0.4 & 0.17 \\
$P_{m}(\mathrm{~W})$ & 0.10 & 0.14 & 0.05 \\
$P_{e}(\mathrm{~W})$ & 0.39 & 0.28 & 0.13 \\
$k\left(s^{-1}\right)$ & 6 & 38 & 35 \\
$t_{m}(\mathrm{~s})$ & 0.03 & 0.01 & 0.005 \\
& & & \\
$\omega_{0}$ & 0.0033 & 0.0039 & 0.0030 \\
$d_{0}(\mu \mathrm{m})$ & 10.5 & 15.4 & 20 \\
$d_{s}(\mu \mathrm{m})$ & 8.3 & 10.9 & 14.5 \\
$t_{0}(\mathrm{~s})$ & 546 & 723 & 883 \\
& & & \\
$t_{5 \%}(\mathrm{~s})$ & 1539 & 2318 & 1977 \\
\hline
\end{tabular}

Table 1: Values of the different parameters appearing in equations (7) and (9) and of $t_{5 \%}$ as functions of the rotational speed.

because for all rotational speeds, the shear rate in the TRM was between $1 s^{-1}$ (in the larger tank space) and $200 \mathrm{~s}^{-1}$ (in the rod-rod space). Furthermore, in this range of shear rates, the viscosity of the final HIPR emulsion was higher than that of the castor oil (as shown hereafter). Thus, the strength applied to the rod to keep the rotational speed constant should be higher than that required by the castor oil alone; however, this was not the case. This could be explained by a thin layer of water adhering to and lubricating the rod. For each rotational speed, we determined the mean drop diameter $\mathrm{dm}$ at different mixing times (Figure 6 ). The experimental data were fitted using equation (7), and the different values of $\omega_{0}, d_{s}, d_{0}$ and $t_{0}$ obtained for each rotational speed are presented in Table 11.

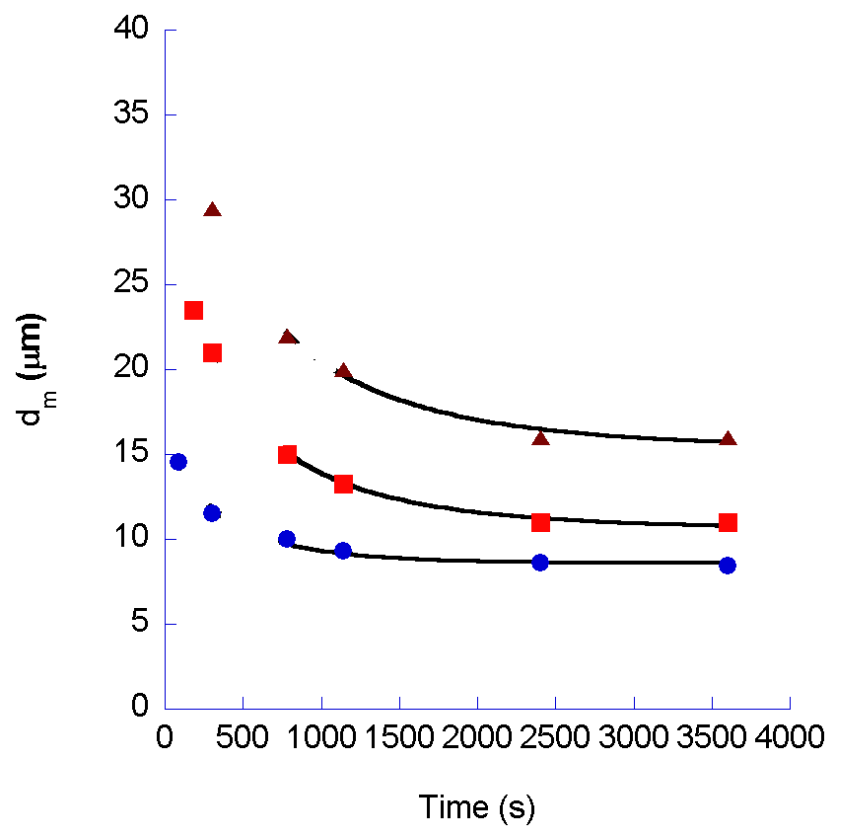

Figure 6: of the mean droplet diameter during mixing for different rotational speeds. $\omega=60 \mathrm{rpm}$ (triangles), $\omega=90 \mathrm{rpm}$ (squares) and $\omega=120 \mathrm{rpm}$ (circles). Experimental points were fitted using equation (7).

The mean droplet radius decreases with increasing rotational speed of the rod. For all rotational speeds, the evolution of the mean drop diameter can be modeled using equation (7), and the rupture 
rate $\omega_{0}$ remains small regardless of the rotational speed of the rod. The initial emulsification time $t_{0}$ also decreases with increasing rotational speed. In each case, the mean droplet diameter remains constant after about 2400 seconds of mixing, and the value of this final droplet diameter is dependent on the rotational speed. A rotational speed of $60 \mathrm{rpm}$ can be used to obtain an emulsion with a mean diameter value ranging between 15 and $30 \mu \mathrm{m}$. In contrast, the rotational speed of $120 \mathrm{rpm}$ only permits the production of a mean droplet diameter lower than $15 \mu \mathrm{m}$.

Here, we can introduce another characteristic time: $t_{5 \%}$, corresponding to the time for which the relative deviation between the mean droplet diameter $d_{5 \%}$ and the final one is equal to $5 \%$ of ds $\left(d_{5 \%}=1.05 d_{s}\right)$. Table 1 gives all of the characteristic times for each rotational speed studied. These characteristic times correspond to the three periods of our emulsification process explained in section 2.2. First, during the macro-mixing time (between $\mathrm{t}=0 \mathrm{~s}$ and $\mathrm{t}=t_{m}$ ), the introduced watersurfactant mixture lubricates the rod but does not disperse in the oil. Next, from $t_{m}$ to $t_{0}$, the droplets of oil are gradually generated in the water to create the primary monodisperse emulsion. Finally, the fragmentation of the emulsion takes place by reducing the mean droplet diameter until the limit value. The last two periods correspond to the ones observed by Mabille et al [19]. By integrating equation (9) between the macro-mixing time tm and a mixing time t, we could determine the evolution of the amount of energy stored in the TRM per unit volume of dispersed phase, $E_{V d}$ (energy density in J. $m^{-3}$, Eq. (11)) for each rotational speed of the rod:

$$
\begin{aligned}
V_{d} \cdot E_{V d}(t) & =\int_{t_{m}}^{t} P_{e}-\left(P_{e}-P_{m}\right) \exp \left[-k\left(t-t_{m}\right)\right] d t \\
E_{V d}(t) & =\frac{P_{e}\left(t-t_{m}\right)-\frac{\left(P_{e}-P_{m}\right)}{k}\left(\exp \left[-k\left(t-t_{m}\right)\right]-1\right)}{V_{d}}
\end{aligned}
$$

In this equation, $V_{d}$ is the volume of the dispersed phase (here, the volume of oil). The others parameters have been previously defined. In Figure 0, we plotted the Sauter diameter as a function of the energy density input for the different rotational speeds studied and for emulsification times ranging between tm and $t_{5} \%$. We have selected these times to account only for the energy used to reach the final mean droplet diameter (about $2400 \mathrm{~s}$ ). During this effective period, The Sauter diameter can be expressed as a function of the energy density using equation (12) to fit the experimental data [14]:

$$
d_{32}=C \cdot\left(E_{V}\right)^{-b}
$$

For each rotational speed, the Sauter diameter decreases with increasing energy density input into the mixer. However, the energy density input necessary to obtain the same value of the Sauter diameter depends on the rotational speed of the rod (Figure 7); likewise, for the same energy density input, the obtained Sauter diameter is dependent upon the rotational speed (Figure 匇). Karbstein and Schubert [13] have obtained HIPR emulsions composed of $80 \%$ rapeseed oil (viscosity: $6.1 \times 10^{-3}$ Pa.s at $20^{\circ} \mathrm{C}$ ) in water using egg yolk as an emulsifier using different mixers: toothed colloid mill, toothed disc dispersing machine and high-pressure homogenizer. We found that to obtain emulsions in the TRM having Sauter diameters equivalent to those obtained by Karbstein and Schubert [13], the necessary energy density is ten times smaller in our process. However, the relationship between the Sauter diameter and the energy density also depends upon the composition of the emulsion; thus, this comparison is only indicative. Effectively, to compare the energy efficiency of the TRM to those of other mixers, we must make emulsions with the same components and the same proportions. Furthermore, to calculate the energy density, Karbstein and Schubert used the relation $E_{V}=\frac{P}{V}$, where $V$ corresponds to the flow rate of the emulsion. For high-pressure homogenizers, Stang et al. [14] have obtained energy densities ten times larger than those obtained by our process for different oil/water viscosity ratios (however, their Sauter diameter is smaller, ranging between 1 and $15 \mu \mathrm{m}$ ).

\subsection{Effect of surfactant type and concentration}

In these experiments, the only variable parameter was the concentration of surfactant used for the emulsification. Two non-ionic surfactants are compared: Triton X-100 and Triton X-405. Emulsions 


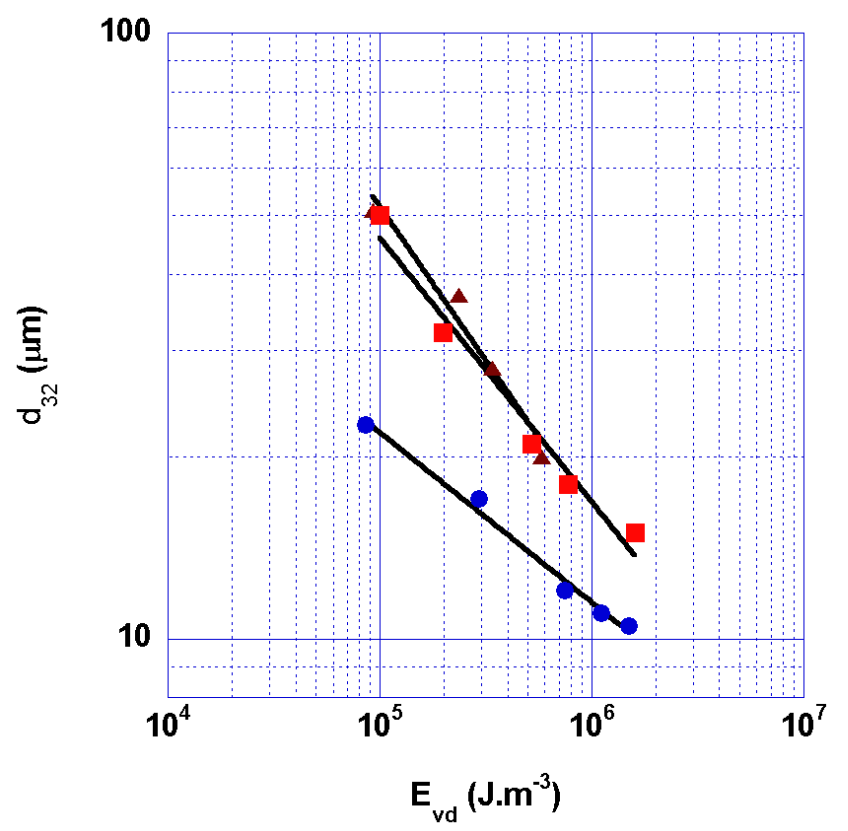

Figure 7: Sauter diameter as a function of energy density EVd for the different rotational speeds: $\omega$ $=60 \mathrm{rpm}$ (triangles), $\omega=90 \mathrm{rpm}$ (squares) and $\omega=120 \mathrm{rpm}$ (circles). The values of the couple (C, b) used in equation (10) are, respectively: $(18085,0.5) ;(6916,0.4) ;(553,0.3)$.

were made with a rotational speed of $90 \mathrm{rpm}$. The emulsification time chosen for the comparison was 780 seconds (13 minutes), which corresponds to the end of the first period of evolution of the mean droplet diameter during the mixing (for $15.9 \mathrm{wt} \%$ of Triton X-405, see section 3.1) and to the time at which the power is stabilized (see section 3.2). For this timepoint, the mean droplet diameters were determined and compared (Figure 8).

For the two studied surfactants, the evolution of the mean droplet diameters presented two regions. In the first time period, the mean droplet diameter decreased rapidly, and in a second one, this diameter decreased slowly towards an asymptote. These two regions have also been observed by Tcholakova et al. 20] for less concentrated emulsions made using turbulent flow with another non-ionic surfactant (Brij 58). For each concentration, emulsions made with Triton X-100 have a mean droplet size smaller than that for the ones made with Triton X-405. The uniformity factor $\mathrm{U}$ has also been determined for each emulsion via equation (5). At low and high concentrations of surfactant, emulsions are monodisperse; however, the ones produced at low concentration (below $4 \mathrm{wt} \%$ of surfactant in water) are unstable. Effectively, coalescence takes place after one day, whereas for emulsions made with higher concentrations of surfactant, the breaking occurred only after several months. All of the HIPR emulsions seemed to be monodisperse, with $U$ values lower than 0.25 .

\subsection{Effect of the mean droplet diameter on the rheological behavior}

We know that the rheological behavior of the emulsions with the same composition is mainly dependent upon the droplet size distribution. Thus, to compare the droplet size distributions between two emulsions, we can compare their rheological behaviors [23]. Figure 9 confirms the influence of the mean droplets radius on the rheological behavior of the HIPR castor Oil-in-Water emulsion obtained in the TRM. At all values of the mean droplet diameter, the viscosity behaviors of these HIPR emulsions (Figure 9) are similar and do not present a Newtonian plateau at low shear rates. These emulsions have a shear thinning behavior in the entire range of the shear rate study. However, there appears to be a break (change in the slope) in this shear thinning behavior for a shear rate value between 0.1 and $1 \mathrm{~s}^{-1}$. This viscosity behavior is the result of the rearrangement of the droplets, which evolve from a state of equilibrium to a state of flow [24]. Moreover, Figure 9 also illustrates the dependence of the mean droplet size on the viscosity value, and, as was already observed [7], the 


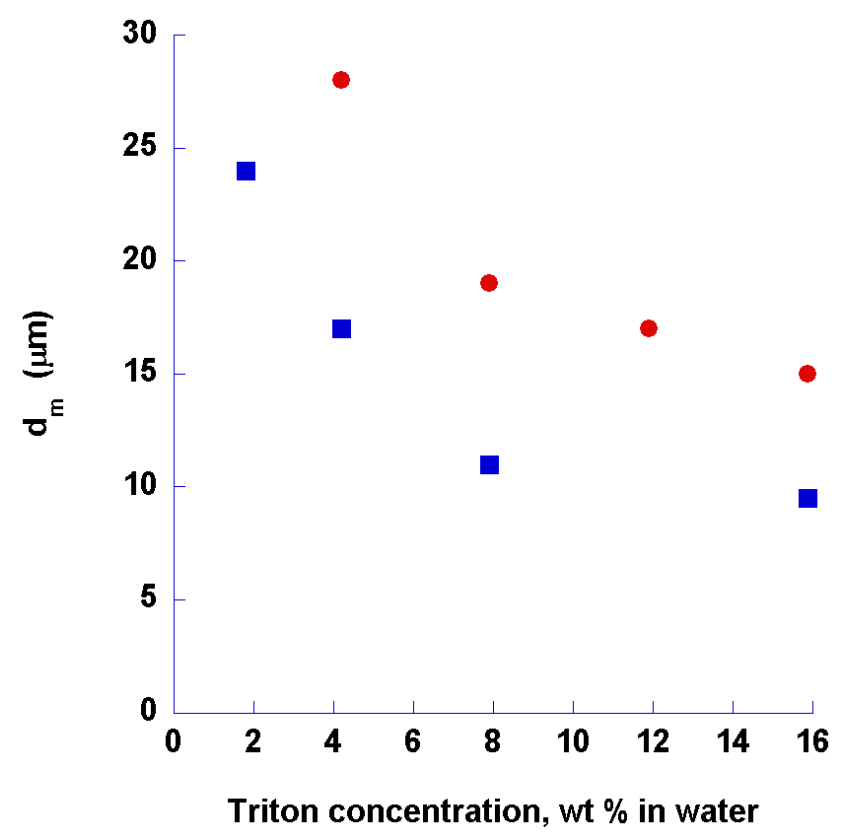

Figure 8: Evolution of (a) the mean droplet diameter and (b) the uniformity factor $U$ as functions of the surfactant concentration for emulsions stabilized by Triton X-100 (squares) and Triton X-405 (circles)

viscosity of the HIPR emulsion increases with decreasing mean droplet radius. The evolution of the storage modulus $G^{\prime}$ and of the loss modulus $G^{\prime \prime}$ as functions of the frequency observed in Figure 9 was also observed by Mason [25] for HIPR emulsions. At an early timepoint, the storage modulus increases until it exhibits a plateau, whereas the loss modulus presents a minimum in the frequency band where the storage modulus plateau appears. This minimum is also a manifestation of the rearrangement of the droplets in the HIPR emulsion. In accordance with the results observed by Langfeld et al. [23], we note a decrease in the elasticity with increasing mean droplet diameter of the HIPR emulsion.

\subsection{Effect of salt}

Within the context of a targeted application, such as petroleum, biomaterial engineering, pharmaceuticals, cosmetics, etc., it was interesting to evaluate the effect of added salt on the emulsification performance of HIPR emulsion via rheological behavior. An HIPR emulsion made with $30 \mathrm{~g} / \mathrm{L}$ of salt in the initial surfactant mixture was compared to one produced classically, both with a rotational speed equal to $90 \mathrm{rpm}$ and with Triton X-405 at a concentration of $15.9 \mathrm{wt} \%$ in water. In section 3.4, we discussed the influence of the mean droplet diameter on HIPR rheological behavior. Here, we compare the effect of shear rate on the viscosity and the evolution of storage and the loss modulus as functions of frequency between the two HIPR emulsions made with and without salt (Figure 10). As was explained previously, these comparisons permit to indirectly compare the mean droplet diameter of these HIPR emulsions.

After 40 minutes of mixing, the evolutions of the viscosity and the stress as functions of the shear rate present similar behaviors for the produced emulsions with and without salt. Likewise, the storage modulus $G^{\prime}$ and the loss modulus $G^{\prime \prime}$ present the same variation as functions of the frequency for both of the emulsions. Thus, we can affirm that, for these mixing conditions, added salt does not affect the emulsification.

\section{Conclusion}

We have studied and characterized several parameters affecting the droplet size distributions of HIPR emulsions produced in a Two-Rod Mixer batch process operating in the laminar flow regime. By 


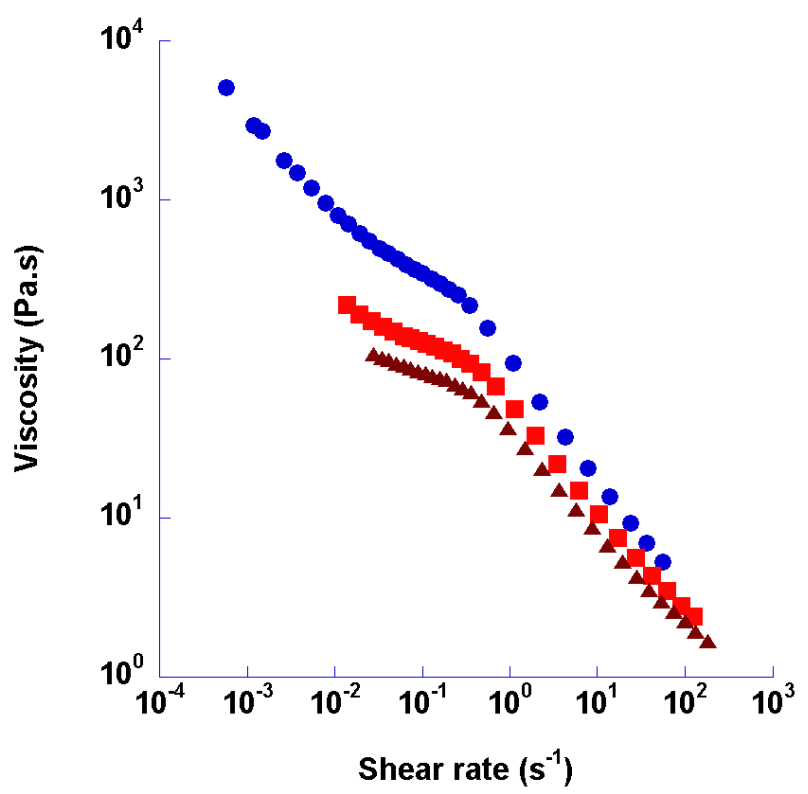

(a)

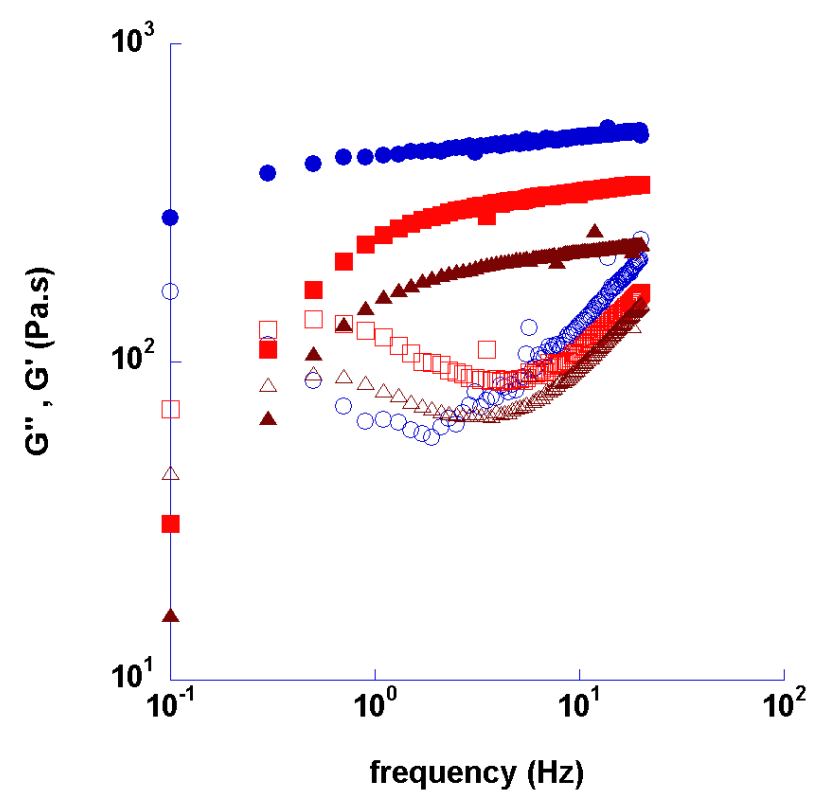

(b)

Figure 9: Comparison of the rheological behaviors between HIPR Castor oil in water emulsions made with Triton X-405 (15.9 wt\% in water) for different mean droplet radii: $d_{m}=8.6 \mu m$ (circles), $d_{m}=11 \mu m$ (squares) and $d_{m}=15 \mu m$ (triangles). (a) Viscosity as a function of shear rate. (b) Evolution of the storage modulus $G^{\prime}$ (closed symbols) and the loss modulus $G^{\prime \prime}$ (open symbols) as functions of frequency.

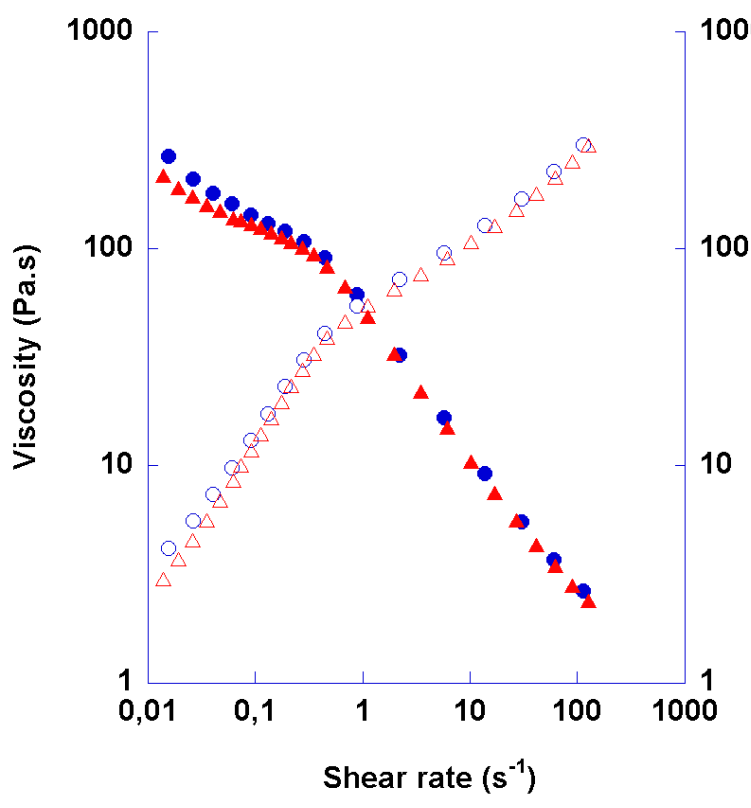

(a)

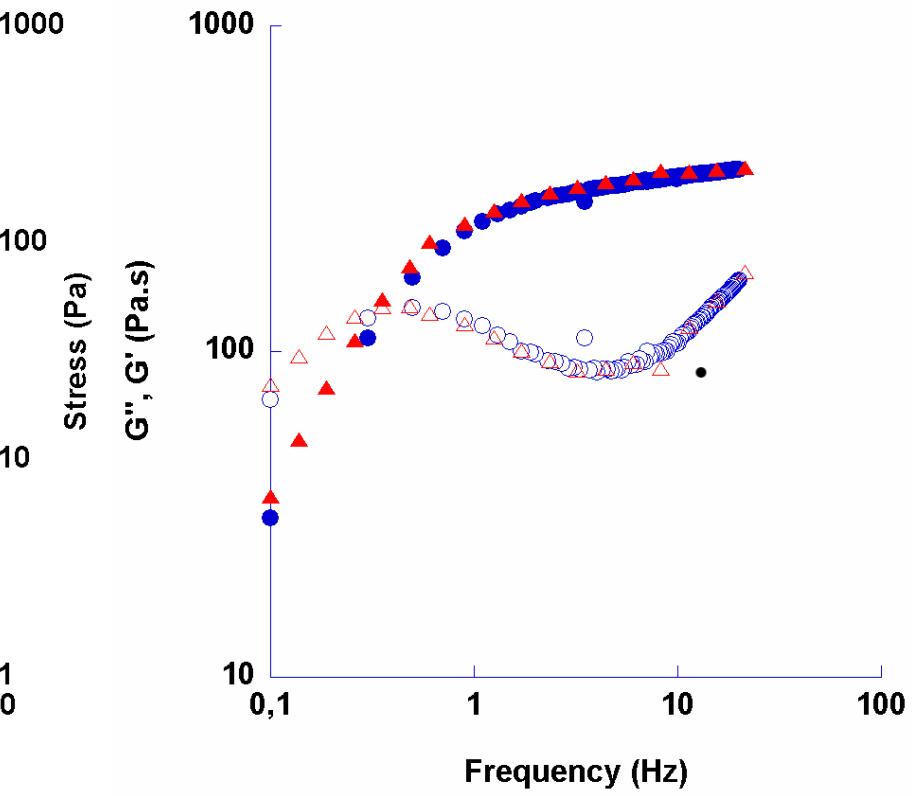

(b)

Figure 10: (a) Viscosity (closed symbols) and stress (open symbols) as functions of shear rate for emulsions made with (triangles) and without (circles) salt. (b) Evolution of the storage modulus $G^{\prime}$ (closed symbols) and the loss modulus $G^{\prime \prime}$ (open symbols) as functions of frequency for emulsions made with (triangles) and without (circles) salt. 
adjusting certain parameters (stirring time, rotational speed, surfactant type and concentration and salt addition), we can control the droplet size distribution and thus the rheological and stability characteristics of the created emulsion. By comparison with other mixing techniques, the droplet size decreases slowly during the mixing time; thus, it is possible to easily obtain emulsions with targeted droplet size distributions. Here, a first comparison has been made of the droplet size as a function of the energy density input, and the Two-Rod mixer batch process seems to consume less energy than do other processes used to obtain similar values of the droplet size. Furthermore, the different periods of HIPR emulsification in the TRM have been highlighted, as well as their characteristics times. First, we have a macro-mixing regime from $\mathrm{t}=0 \mathrm{~s}$ (when the water and surfactant mixture is introduced into the tank) to $\mathrm{t}=t_{m}$. Next, the emulsification begins, and we obtain a first monodisperse emulsion at the time $\mathrm{t}=$ $t_{0}$. Finally, in the last regime, droplets of this initial monodisperse emulsion are gradually broken, and the mean droplet diameter decreases progressively to reach a limit value. Another advantage of the TRM is that the relatively slow rotational speed of the rod prevents unsuitable heating of the fluids during the emulsification process. This eliminates the need for a final step of cooling of the emulsion encountered in more classical processes that use turbulent flows with high rotational velocities.

\section{Acknowledgments}

We would like to gratefully acknowledge Marc Rivalleto and Daniel Champier from the UPPA technical center "Innov'Adour" for their help during the building and the instrumentation of the Two-Rod Mixer batch process. This work was supported by a Graduate Fellowship (S.C.) from the Communauté d'Agglomération Pau-Pyrénées (CDAPP).

\section{References}

[1] Kizling J, Kronberg B, Eriksson J. On the formation and stability of high internal phase O/W emulsions. Advances in colloid and interface science. 2006;123:295-302.

[2] Fournanty S, Le Guer Y, El Omari K, Dejean J. Laminar Flow Emulsification Process to Control the Viscosity Reduction of Heavy Crude Oils. Journal of Dispersion Science and Technology. 2008;29:1355-1366.

[3] Princen H, Aronson M, Moser J. Highly concentrated emulsions, II. Real systems. The effect of film thickness and contact angle on the volume fraction in creamed emulsions. J Colloid Interface Sci. 1980;75(1):246-270.

[4] Princen H. Rheology of foams and highly concentrated emulsions. II: Experimental study of the yield stress and wall effects for concentrated oil-in-water emulsions. Journal of colloid and interface science. 1985;105(1):150-171.

[5] Princen H, Kiss A. Rheology of foams and highly concentrated emulsions. IV: An experimental study of the shear viscosity and yield stress of concentrated emulsions. Journal of colloid and interface science. 1989;128(1):176-187.

[6] Welch C, Rose G, Malotky D, Eckersley S. Rheology of high internal phase emulsions. Langmuir. 2006;22(4):1544-1550.

[7] Malkin A, Masalova I, Slatter P, Wilson K. Effect of droplet size on the rheological properties of highly-concentrated w/o emulsions. Rheologica Acta. 2004;43(6):584-591.

[8] Masalova I, Malkin A, Ferg E, Kharatiyan E, Taylor M, Haldenwang R. Evolution of rheological properties of highly concentrated emulsions with aging-Emulsion-to-suspension transition. Journal of Rheology. 2006;50:435.

[9] Cuellar I, Bullón J, Forgarini A, Cardenas A, Briceno M. More efficient preparation of parenteral emulsions or how to improve a pharmaceutical recipe by formulation engineering. Chemical engineering science. 2005;60:2127-2134. 
[10] Otsubo Y, Prud'homme R. Effect of drop size distribution on the flow behavior of oil-in-water emulsions. Rheologica Acta. 1994;33(4):303-306.

[11] Yaghi B. Rheology of oil-in-water emulsions containing fine particles. Journal of Petroleum Science and Engineering. 2003;40(3-4):103-110.

[12] Gingras J, Fradette L, Tanguy P, Jorda E. Concentrated bitumen-in-water emulsification in coaxial mixers. Ind Eng Chem Res. 2007;46:1818-1825.

[13] Karbstein H, Schubert H. Developments in the continuous mechanical production of oil-in-water macro-emulsions. Chemical Engineering \& Processing: Process Intensification. 1995;34(3):205211.

[14] Stang M, Schuchmann H, Schubert H. Emulsification in high-pressure homogenizers. Engineering in Life Sciences. 2001;1(4).

[15] Gingras J, Fradette L, Tanguy P, Bousquet J. Inline bitumen emulsification using static mixers. Ind Eng Chem Res. 2007;46(8):2618-2627.

[16] Salager J, Forgiarini A, Márquez L, Peña A, Pizzino A, Rodriguez M, Rondon-Gonzalez M. Using emulsion inversion in industrial processes. Advances in colloid and interface science. 2004; 108:259-272.

[17] Paillet S, Grassl B, Desbrières J. Rapid and quantitative determination of critical micelle concentration by automatic continuous mixing and static light scattering. Analytica Chimica Acta. $2009 ; 636(2): 236-241$.

[18] Hait S, Moulik S. Determination of critical micelle concentration (CMC) of nonionic surfactants by donor-acceptor interaction with lodine and correlation of CMC with hydrophile-lipophile balance and other parameters of the surfactants. Journal of Surfactants and Detergents. 2001;4(3):303309.

[19] Mabille C, Leal-Calderon F, Bibette J, Schmitt V. Monodisperse fragmentation in emulsions: Mechanisms and kinetics. Europhysics Letters. 2003;61(5):708-714.

[20] Tcholakova S, Denkov N, Danner T. Role of surfactant type and concentration for the mean drop size during emulsification in turbulent flow. Langmuir. 2004;20(18):7444-7458.

[21] Mason TG, Bibette J. Emulsification in Viscoelastic Media. Phys Rev Lett. 1996;77(16):34813484 .

[22] Sanchez M, Berjano M, Guerrero A, Gallegos C. Emulsification rheokinetics of nonionic surfactant-stabilized oil-in-water emulsions. Langmuir. 2001;17(18):5410-5416.

[23] Langenfeld A, Schmitt V, Stébé M. Rheological behavior of fluorinated highly concentrated reverse emulsions with temperature. Journal of colloid and interface science. 1999;218(2):522-528.

[24] Saiki Y, Prestidge C. Droplet deformability and emulsion rheology: steady and dynamic behavior. Korea-Australia Rheology Journal. 2005;17(4):191-198.

[25] Mason T. New fundamental concepts in emulsion rheology. Current Opinion in Colloid 83 Interface Science. 1999;4(3):231-238. 